Derecho empresarial 



\title{
Algunos apuntes sobre las operaciones societarias de escisión
}

\author{
Oswaldo Hundskopf Exebio
}

\section{Evolución histórica de la regulación jurídica de la institución denominada escisión de sociedades}

El origen de la institución jurídica denominada escisión de sociedades puede hallarse como parte del fenómeno económico de concentración empresarial que surgió a mediados del siglo XIX y alcanzó una gran dimensión en el siglo XX, constituyendo, junto con la fusión, una interesante modalidad de reorganización societaria, ambas muy utilizadas actualmente, y de gran proyección.

Como señala Elías (2001):

Por múltiples razones, algunas veces hasta contradictorias entre sí, las empresas procuran lograr una concentración de capitales, organizaciones, tecnologías, esfuerzos y socios que les permitan conseguir estructuras más adecuadas a sus necesidades de desarrollo, o que las hagan más aptas para responder al reto de la competencia o para mejorar su posición en el mercado. La fusión es quizá la forma más completa creada por el derecho para contribuir a la consecución de las concentraciones empresariales. (p. 736)

El mismo autor (Elías, 2001), refiriéndose específicamente a la escisión de sociedades, señala que: 
[...] en la misma medida en que las concentraciones y fusiones aportaban una serie de resultados positivos para las empresas agrupadas, empezaron a aparecer determinados efectos perniciosos como producto del crecimiento. La organización empresarial agrupada tiende a perder dinamismo, lo que puede convertirse, con el tiempo, en ineficiencia de la empresa. La administración de la gran empresa fusionada termina destinando cada vez más recursos a administrarse ella misma, antes que dedicarlos a mejorar o a aumentar la producción. Otras veces se encuentra obligada a desarrollar un conjunto de nuevas actividades que antes no tenía, pues la empresa gigante tiende a incursionar en negocios vinculados, paralelos o distintos a los de su actividad original. Ante estos nuevos problemas, que muchas veces no se vislumbran al iniciarse un proceso de fusión o concentración, surge la imperiosa necesidad de reorganizar la empresa o las empresas del grupo, y reencontrarse con la dinámica y la eficiencia que antes demostraban. De esta manera, un proceso de fusión o concentración genera a menudo la necesidad de reorganizar la empresa o las empresas del grupo. Allí aparece la escisión, que es uno de los mecanismos más importantes de las reorganizaciones societarias. (p. 782)

Por su parte, Otaegui (1981) expresa lo siguiente:

La realidad es que en un grado de concentración empresarial, al conllevar el inevitable gigantismo de la empresa y de la organización, requiere para el mantenimiento de su eficiencia productiva que se proceda a una descentralización no empresarial pero sí organizativa. (p. 236)

La escisión es en nuestro país y en el mundo entero una de las figuras principales dentro de lo que se conoce en doctrina y legislación comparadas como "reorganización de sociedades". Según el Diccionario de la Real Academia Española (2001), el término "reorganización" es definido como "Acción y efecto de reorganizar"; el mismo Diccionario contempla dos definiciones para el vocablo "reorganizar": "Volver a organizar algo" y "Organizar algo de manera distinta y que resulte más eficaz".

Respecto de la reorganización societaria, Castle Álvarez-Maza (2002) señala lo siguiente:

En sentido mercantil y empresarialmente hablando, la reorganización constituye un objetivo, derivado de un sin número de motivos, principalmente de tipo económico y administrativo, destinados a la alteración de estructuras empresariales y legales tendientes a la concentración, división o a la eficiente prosecución de algún otro objetivo 
empresarial. [...] En efecto, la finalidad del derecho societario en el campo de la reorganización empresarial debe tender a generar los canales de comunicación entre los objetivos comerciales, financieros, administrativos, o de cualquier otra índole que la empresa busca en su reorganización y las estructuras legales-societarias que soportan a la empresa, respectivamente, independientemente de la entidad legal que la envuelve. De ahí que la doctrina y la legislación relacionada con las distintas ciencias y disciplinas que se ocupan del fenómeno de la reorganización empresarial son, a nuestro entender, la base sobre la que se apoya la reorganización de sociedades. No podemos por tanto desligar una de la otra. (p. 256)

Según la opinión mayoritaria de la doctrina ${ }^{1}$ que compartimos, el antecedente más importante que existe sobre regulación de la escisión se encuentra en el derecho francés. En efecto, según señala el tratadista argentino Verón (2008):

El derecho francés es el que ha regulado con mayor detalle la institución de la escisión, remontándose a los años 1949 y 1952, y constituyendo la práctica administrativa -por imperativo de razones económicas-, lo que motivó la aplicación del tratamiento fiscal de la fusión al de la escisión; práctica que fue recogida luego en el ámbito notarial, incorporada después en el proyecto de ley de sociedades, y finalmente consagrada en el derecho positivo en la ley de 1966. (p. 116)

El autor se refiere a la ley francesa 66.537, del 24 de julio de 1966, y sus posteriores modificatorias. El mismo autor (Verón, 2008), refiriéndose al caso argentino, señala:

La receptación del instituto de la escisión, que en nuestro medio tuvo origen fiscal, no permite apartarnos de lo que el legislador conformó como tal en la norma contenida en el art. 88 de la ley 19.550. Más adelante, al reconsiderarse el Proyecto de la Ley de Sociedades Comerciales que la comisión redactora elevara el 23/12/68, entre las innovaciones incorporadas al Proyecto anterior se cuenta la regulación de la escisión a tenor del contenido del art. 88, versión original. (p. 117)

En el caso brasileño, tenemos como antecedente normativo la Ley 6406 del año 1976.

1 Un sector minoritario de la doctrina encuentra el antecedente más remoto de la escisión en la figura de la incorporazione, proveniente del derecho italiano. 
En España, la escisión estaba regulada en el ámbito tributario, en la Ley 43/1995, de 27 de diciembre de 1995, sobre el Impuesto sobre Sociedades. Posteriormente, los conceptos de fusión y escisión, que no se encontraban regulados en la Ley de Sociedades Anónimas de 1951, fueron incorporados en la Ley de Sociedades Anónimas de 1989, como parte de la adaptación de la legislación societaria al derecho comunitario europeo, y en concreto a la Tercera Directiva sobre Derecho de Sociedades (78/855/CEE de 9 de octubre) y la Sexta Directiva sobre Escisión de Sociedades Anónimas (82/891/CEE de 17 de diciembre).

En cuanto al tratamiento legislativo de la escisión de sociedades en el Perú, la anterior Ley General de Sociedades², siguiendo el esquema de la Ley de Sociedades Anónimas española de 1951, únicamente regulaba la transformación de sociedades en la sección segunda (artículos 346 al 353) del Libro III, y la fusión de sociedades en la sección tercera (artículos 354 al 358) del mismo libro, y por lo tanto no se ocupó de la escisión de sociedades y de otras formas de reorganización de sociedades. En el caso de la transformación, la ley anterior únicamente contemplaba la posibilidad de que las sociedades constituidas legalmente puedan transformarse en cualquiera de las otras clases de sociedades consideradas en la ley, sin cambiar su personalidad jurídica.

A partir del $1^{\circ}$ de enero de 1998, fecha de entrada en vigencia de la Ley n. ${ }^{\circ}$ 26887, Ley General de Sociedades (en adelante, simplemente LGS), existe en nuestro país una regulación moderna, sistemática y detallada de las operaciones que pueden agruparse bajo la denominación "reorganización de sociedades", y que es parte del Libro IV, denominado "Normas complementarias". Dentro de la sección segunda de dicho libro, específicamente en su Título III, están los artículos 367 al 390, que constituyen la regulación sobre la escisión.

En efecto, la Comisión Redactora de la LGS consideró conveniente incorporar una sección dedicada a la reorganización de sociedades, en la que se incorporasen y regulasen adecuadamente las operaciones que

2 Ley de Sociedades Mercantiles n. ${ }^{\circ}$ 16123, promulgada el 27 de julio de 1966. Posteriormente, mediante Decreto Supremo n. ${ }^{0} 311$, publicado el 13 de noviembre de 1984, se modificó la Ley de Sociedades Mercantiles, transformándosela en Ley General de Sociedades. Por Decreto Supremo n. ${ }^{\circ}$ 003-85-JUS, publicado el 13 de mayo de 1985, se aprobó el Texto Único Concordado de la Ley General de Sociedades, que estuvo vigente hasta el 31 de diciembre de 1998. 
venían llevándose a cabo en la práctica empresarial, pero que no contaban con regulación expresa en la normatividad societaria.

Así, en la sección segunda del Libro IV de la LGS se regulan, bajo el título "Reorganización de sociedades", las siguientes formas de reorganización de sociedades:

1. Transformación (Título I, artículos 333 al 343).

2. Fusión (Título II, artículos 344 al 366).

3. Escisión (Título III, artículos 367 al 390).

4. Otras formas de reorganización (Título IV, artículos 391 al 395), que comprende: (i) reorganización simple; (ii) escisiones múltiples; (iii) escisiones múltiples combinadas; (iv) escisiones combinadas con fusiones, entre las mismas sociedades participantes; (v) escisiones y fusiones combinadas entre múltiples sociedades; (vi) cualquier otra operación en que se combinen transformaciones, fusiones o escisiones; (vii) reorganización de sociedades constituidas en el extranjero; y (viii) reorganización o transformación de la sucursal de una sociedad constituida en el extranjero.

Adicionalmente, dentro del marco legal de la reorganización de sociedades, es necesario mencionar el Reglamento del Registro de Sociedades, aprobado por Resolución n. ${ }^{\circ}$ 200-2001-SUNARP/sn, publicado en el diario oficial El Peruano el 27 de julio de 2001 (en adelante, simplemente RRS), que no siendo un reglamento propiamente dicho de la LGS, regula, según su artículo 1, las inscripciones que se realizan en el Registro de Sociedades, y a las cuales se aplican los principios registrales previstos en su texto. Es específicamente en el capítulo segundo del Título IV, donde se han incluido, en subcapítulos independientes, disposiciones legales sobre la transformación, la fusión, la escisión, la reorganización simple, las reorganizaciones de sociedades constituidas en el extranjero y la reorganización de sucursales establecidas en el Perú, de sociedades constituidas en el extranjero.

Finalmente, en materia tributaria, conforme a los artículos 103 de la Ley del Impuesto a la Renta y 65.b de su norma reglamentaria, se reconocen como escisiones a aquellas formas de reorganización societaria establecidas en el artículo 367 de la LGS, y para los efectos del Impuesto General a las Ventas les son aplicables los artículos 2 inciso c y 2 inciso 7 de la Ley y de su Reglamento respectivamente. 


\section{Naturaleza jurídica de la escisión}

La escisión, como una de las formas de reorganización de sociedades, es definida por Richard y Muiño (2004), en el derecho argentino, como: “... una forma de organización de la actividad económica de una o varias sociedades, mediante la adopción de una nueva organización jurídica, que supone un desprendimiento patrimonial" (p. 843).

Por su parte, en el derecho colombiano, Reyes (2006) comenta:

La escisión de una sociedad puede definirse como la división de su patrimonio social en dos o más partes, a fin de traspasar en bloque una, varias, o la totalidad de estas partes resultantes de la división a una o varias sociedades preexistentes o constituidas a raíz de esta operación, recibiendo los accionistas de la sociedad escindida, acciones o participaciones de las sociedades beneficiarias en contraprestación a esta aportación. (p. 180)

A su vez, en el derecho español, Broseta (2009) afirma:

La función económica de la escisión es compleja. Se trataría, en una de sus formas, de dividir o separar, en dos o más partes, el patrimonio de una sociedad (que se extingue), para aportar cada una de ellas a una o varias sociedades nuevas o preexistentes. Se aprecia, pues, que la escisión puede ser un medio para conseguir una desconcentración de las partes de un todo empresarial (la sociedad escindida) para proceder a una integración en las sociedades beneficiarias (por creación o absorción). (p. 585)

En el Perú, la LGS llevó a cabo una trascendental innovación, reconociendo e incorporando a la escisión de sociedades como una forma de reorganización de sociedades, y es que, en algunos casos, una determinada sociedad preexistente o la organización empresarial creada por una fusión por incorporación, puede ocasionar efectos colaterales imprevisibles, llegando a perder el dinamismo y eficacia que se tenía como propósito para su constitución; es ahí donde surge la escisión como un medio de reorganización para brindar la solución a este tipo de problemas.

Como bien señala Elías (2001, p. 969), los artículos 367 al 390 de la LGS, introducen en la legislación societaria peruana una novísima regulación de los procesos de escisión ocupándose del concepto, de las formas legales en que pueden realizarse, y de establecer con todo detalle el procedimiento que deben cumplir las personas jurídicas que deseen participar en una operación de este tipo. 
Con dicha incorporación se ha llenado el vacío que existía en nuestro ordenamiento legal societario, regulándose ahora una institución que viene a ser opuesta a la fusión y que constituye una expresión de la desconcentración empresarial, institución que se encontraba normada en todos los ordenamientos legales de nuestro continente, excepto en nuestro país. Se le conoce también como división o fraccionamiento de sociedades.

Siguiendo a Beaumont (1998, pp. 625-626.), la escisión persigue, entre sus múltiples fines:

- La solución de los conflictos internos entre los diferentes grupos de socios de la sociedad, como una alternativa a su liquidación.

- La solución a un crecimiento exagerado o imprudente de las unidades o conjuntos empresariales.

- La especialización de las distintas actividades que realiza la empresa, separando cada una de ellas en unidades económicas y jurídicamente independientes; en otras palabras, buscando la descentralización empresarial.

- Descentralización de las actividades realizadas por la sociedad en varias áreas geográficas.

- El saneamiento de una sociedad que ejerce dos o más actividades empresariales, una de las cuales carece de viabilidad.

Como puede apreciarse, la escisión es un mecanismo de reorganización empresarial que permite lograr objetivos muy diversos, que afectan tanto a las sociedades que participan en el proceso como a sus socios o accionistas, bajo un esquema de reducir los costos. En efecto, una de las principales razones que motivó la regulación de la figura de la escisión es la simplificación del proceso de reorganización societaria y la reducción de costos (pues si no existiera la escisión se tendría que constituir una nueva sociedad o adquirir las acciones de una existente a la cual transferir los activos, lo que incrementa los costos de negociación y ejecución).

Para Israel Llave y Filomeno Ramírez (2003, p. 1180), la escisión suele presentarse como una alternativa jurídica para conseguir la reestructuración económica de la sociedad y alcanzar, por ejemplo, la desconcentración y especialización de la empresa. Coincidiendo con dichos autores, la desconcentración en varias unidades jurídicas facilita una mayor flexibilidad y adecuación de la financiación de las explotaciones separadas, y la especialización permite la realización de actividades económicas con mayor eficiencia. Adviértase que la propia LGS permite 
expresamente la escisión de sociedades de cualquier forma o tipo, por estar regulada dentro del Libro IV de la LGS, en el cual se establecen las normas complementarias aplicables a todas las formas societarias.

Desde una óptica tributaria, Bravo (2003), en su ponencia sobre la escisión subjetiva en el ordenamiento jurídico peruano, expresa lo siguiente:

Teniendo en cuenta el derecho de los empresarios a modificar estructuralmente sus sociedades para hacerlas más eficientes y rentables, y atendiendo al hecho que ello no supone en rigor una ganancia, toda vez que el valor total de las acciones resultantes de la modificación societaria sigue siendo el mismo, la idea de neutralidad fiscal se alinea con la de no generarle obstáculos, y que en lugar de ello, el ordenamiento jurídico tributario facilite las reorganizaciones societarias, inafectando las transferencias del patrimonio, permitiendo el diferimiento de los resultados imponibles y las transferencias de saldos a favor y créditos fiscales. (p. 131)

En opinión de dicho autor, la neutralidad fiscal en materia de reorganizaciones societarias no tiene la talla de un principio jurídico, sino que es una regla de derecho que materializa una política fiscal de no obstaculizar, y, por el contrario, pretende favorecer los procesos de reorganización.

Atendiendo al marco legal y conceptual arriba expuesto, tenemos que, respecto de la naturaleza jurídica de la escisión de sociedades, existen actualmente dos grandes corrientes doctrinarias:

- Una corriente contractualista, según la cual, al ser la sociedad esencialmente un contrato, la escisión también lo es, es decir, es un contrato entre las sociedades participantes en virtud del cual se acuerda la segregación de uno o más bloques patrimoniales, que serán transferidos en favor de una o más sociedades existentes; o utilizados para la creación de una o más sociedades nuevas. En el contrato de escisión se establecen aspectos como la relación de canje, la valorización del o los bloques patrimoniales a transferir, entre otros.

- Una corriente corporativista o de decisión corporativa, según la cual la escisión es un negocio jurídico corporativo, que aun cuando parte de la base de un acto negociado entre las sociedades participantes (proyecto de escisión), se produce y surte efectos unilateralmente al interior de cada sociedad, al momento de adoptar, el órgano societario competente, el acuerdo de escisión. 
Por nuestra parte, como hemos sostenido en trabajos previos ${ }^{3}$, consideramos que la naturaleza jurídica de la escisión no puede limitarse o agotarse afirmando que se trata de un simple contrato. Por el contrario, consideramos que la escisión es una institución societaria compleja que, si bien tiene origen negocial o contractual, se configura como un acto corporativo, adoptado por los órganos competentes de cada una de las sociedades intervinientes.

Ahora bien, independientemente de la posición que se adopte respecto de la naturaleza jurídica de la escisión, en nuestra opinión, está claro que se trata de un acto jurídico ${ }^{4}$ (entendido, conforme al artículo 140 del Código Civil peruano, como "manifestación de voluntad que tiene por objeto crear, modificar o extinguir relaciones jurídicas") que se configura de la siguiente manera:

a) Respecto del proyecto de escisión a que se refieren los artículos 371 y 372 de la LGS, al pactarse los términos y condiciones de dicho proyecto, que posteriormente debe ser aprobado por los directorios o, en las sociedades que no tienen dicho órgano social, por la mayoría absoluta de los administradores de todas las sociedades participantes, y que, en nuestra opinión, tiene la naturaleza de un acto previo o preparatorio de la escisión.

b) Respecto de la escisión propiamente dicha, al adoptarse el acuerdo de escisión a que se refiere el artículo 376 de la LGS, por parte de las juntas generales de accionistas o asambleas de todas las sociedades participantes, previo cumplimiento de los requi-

3 “Un tema recurrente que llama la atención en las tres resoluciones recaídas en el proceso que terminó con la Casación 275-2007 es la calificación que se le da a la escisión, considerándola como un 'acuerdo', 'convenio' o 'contrato', aun cuando, efectivamente, en virtud de ella se transfieren bloques patrimoniales. La escisión es mucho más que un simple acuerdo, siendo una institución societaria de singular importancia y que constituye una de las modalidades de reorganización societaria, con reglas especiales de procedimiento, que, como se ha visto a lo largo del comentario desarrollado, implican una serie de etapas, requisitos y formalidades que terminan con una única escritura pública que debe inscribirse en el registro público". (Hundskopf, 2009, p. 210)

4 Prescindimos intencionalmente, para efectos del presente trabajo, del debate doctrinario entre el concepto de "acto jurídico" y el de "negocio jurídico", para atenernos a la terminología utilizada por el Código Civil vigente. 
sitos de convocatoria e información a que se refieren los artículos 374 y 375 de la LGS.

\section{Caracteres esenciales de la escisión}

Según Menéndez García ${ }^{5}$, puede decirse que la escisión es aquella modificación estructural de una sociedad, en virtud de la cual se produce la división del patrimonio social en dos o más partes, produciéndose el traspaso de uno o más bloques patrimoniales a una o varias sociedades preexistentes, o nuevas, sin que la sociedad que se escinde perciba contraprestación alguna como producto de dicho traspaso. Como vemos, dicha definición no se contradice y por lo tanto va en la línea de la definición contenida en el artículo 367 de la LGS, según la cual, por la escisión, una sociedad fracciona su patrimonio en dos o más bloques para transferirlos íntegramente a otras sociedades o para conservar uno de ellos, cumpliendo los requisitos y las formalidades prescritas por dicha ley.

En consecuencia, la escisión puede adoptar algunas de las siguientes formas:

- Escisión por división, también llamada escisión "propia" o "total", que es la forma prevista en el numeral 1 del artículo 367 de la LGS, y que se da cuando la empresa que decide escindirse divide la totalidad de su patrimonio en dos o más bloques, para trasladarlos a una nueva o nuevas sociedades, o a una o más sociedades ya existentes, o ambas cosas a la vez, produciendo la extinción de la sociedad que se escinde, la cual pierde su personalidad jurídica.

- Escisión por segregación, también llamada "impropia" o "parcial", que es la forma prevista en el numeral 2 del artículo 367 de la LGS, en la que la sociedad que decide escindirse, sin extinguirse, divide su patrimonio en uno o más bloques patrimoniales para transmitirlos a una o más sociedades nuevas, o para ser absorbida por sociedades existentes, o ambas cosas a la vez, ocasionando un ajuste de su capital en el monto correspondiente, sin que se produzca la extinción.

5 Menéndez García, Aurelio, citado por Bravo, J. (2003). 
En ambos casos, señala el artículo 367 de la LGS en su último párrafo, que los socios o accionistas de las sociedades escindidas, reciben acciones o participaciones como accionistas o socios de las nuevas sociedades o sociedades absorbentes, en su caso.

Siguiendo en este punto a la doctrina española más autorizada (Uría, Menéndez \& Iglesias, 1999, p. 1270), que ha sido la principal fuente de inspiración de la vigente regulación peruana sobre la materia, tenemos que los elementos comunes a todos los tipos de escisión existentes, son los siguientes:

a) La transmisión a las sociedades beneficiarias de las partes en que se divida el patrimonio de la sociedad escindida y que se hace en bloque y por sucesión universal. En el proyecto de escisión, que es un elemento de singular importancia, en el procedimiento correspondiente, tiene que figurar una mención relativa a la designación y el reparto preciso, de los elementos del activo y del pasivo, que han de transmitirse a cada una de las sociedades beneficiarias.

En cuanto a la transmisión del bloque patrimonial, Reyes (2006) indica:

Como ocurre en toda escisión, la porción patrimonial dividida se transfiere en bloque a la sociedad o sociedades beneficiarias. Esta transmisión sub especie universalitatis, implica que todos los efectos económicos y jurídicos operan en forma automática a partir de dicha transferencia. No es, por tanto, necesaria la enajenación individualizada de los elementos del activo, ni la subrogación de deudas a favor de la beneficiaria, ni la novación de cada una de las obligaciones que forman parte del pasivo segregado. Un solo acto jurídico es suficiente para que se entienda sustituido el deudor o acreedor y para que se transfiera el complejo de relaciones jurídicas inherentes a la parte patrimonial fraccionada. (p. 193)

En ese orden de ideas, la transmisión en bloque del patrimonio opera de manera directa, por imperio de la norma, y produce la subrogación de la sociedad beneficiaria en la posición antes ocupada por la sociedad escindida, y de esta manera, la sociedad beneficiaria reemplaza a la sociedad escindida. Así lo dispone, en nuestro país, el artículo 378 de la LGS, que, al referirse a la fecha de entrada en vigencia de la escisión, señala:

A partir de esa fecha las sociedades beneficiarias asumen automáticamente las operaciones, derechos y obligaciones de los bloques patri- 
moniales escindidos y cesan con respecto a ellos las operaciones, derechos y obligaciones de la o las sociedades escindidas, ya sea que se extingan o no.

b) Como contraprestación de la atribución de los elementos patrimoniales de la sociedad escindida a la o las sociedades beneficiarias, éstas entregarán o atribuirán a los socios de aquélla, acciones, participaciones o cuotas sociales propias en la proporción que a cada uno corresponda, según la relación o tipo de canje establecido para cada caso en el proyecto de escisión.

Es importante tener en cuenta que existen ciertas reglas comunes aplicables tanto a la escisión por división como a la escisión por segregación, que pasamos a detallar a continuación:

- Los socios o accionistas de las sociedades que se escinden son los que reciben las acciones o participaciones como accionistas o socios de las nuevas sociedades, o sociedades beneficiarias en su caso.

- En ambos casos, la transferencia de bloques patrimoniales se hace a favor de sociedades que se constituyen para tal efecto, a favor de sociedades preexistentes, o a ambas a la vez.

- Cuando concurran sociedades preexistentes, con la escisión se generará un aumento de capital en las sociedades que absorben los bloques patrimoniales, que, por tener un determinado valor, incrementan su patrimonio; empero, existen diversos supuestos de excepción al aumento, señalando, entre otros casos, cuando la sociedad beneficiaria es titular de todas o de parte significativa y mayoritaria de las acciones o participaciones de la sociedad escindida, o cuando el "valor neto" del bloque patrimonial transferido es cero, o es negativo, supuesto al que nos referiremos más adelante.

Para los efectos de la escisión, según el artículo 369 de la LGS, se entiende por bloques patrimoniales a un activo o un conjunto de activos de la sociedad escindida, al conjunto de uno o más activos y uno o más pasivos, o a un fondo empresarial. Por ello, en nuestro país, es posible que una escisión suponga la transferencia de un bloque patrimonial compuesto exclusivamente por un activo.

c) En consonancia con el marco de regulación que se inserta en la disciplina legal de la escisión, la Ley exige, como presupuesto para que se pueda acordar válidamente la escisión de la sociedad anónima, que las acciones de la sociedad que se escinde se encuentren total- 
mente desembolsadas. Es importante mencionar al respecto que en el caso peruano, este no es un requisito que haya sido establecido expresamente para el caso de la escisión de sociedades. Sin embargo, en el caso de escisiones en las cuales la o las sociedades extinguidas sean preexistentes, podría interpretarse que la escisión implica un aumento de capital por "nuevos aportes" ${ }^{6}, \mathrm{y}$, en consecuencia, sería aplicable el requisito previo según el cual la totalidad de las acciones suscritas, cualquiera sea la clase a la que pertenezcan, se encuentre totalmente pagada, previsto por el artículo 204 de la LGS.

d) Adicionalmente, en el supuesto de la escisión división, también llamada escisión propia o total, la sociedad escindida se extingue como consecuencia de la división y atribución de su patrimonio a las sociedades beneficiarias. Mas es precisamente la ausencia de este efecto extintivo, en el caso de la escisión segregación o escisión impropia, lo que permite concluir que la extinción de la sociedad escindida no es un presupuesto necesario de la operación, ni constituye un elemento integrante de su concepto.

Respecto del tema, Elías (2001) menciona, entre los que considera como caracteres esenciales de la escisión, a los siguientes:

a) La extinción de la persona jurídica escindente, sin disolución ni liquidación, en la escisión división total o propia. Sobre el particular, el autor indica:

Hace bien la LGS, en nuestra opinión, al referirse expresa y exclusivamente a la extinción (y no a la disolución) de la sociedad que se escinde en forma total, en el artículo 367, bajo comentario. Más adelante, enfatizando la opción legislativa tomada, establece en el artículo 370 que no se requiere acordar la disolución y no se liquida la sociedad o sociedades que se extinguen por la escisión. Y, ratificando nuevamente el mismo principio, el artículo 378 determina que, por el solo hecho de la inscripción en el Registro, se produce la extinción automática de la sociedad escindida. (Elías, 2001, p. 804)

6 Utilizamos las comillas debido a que, en nuestra opinión, no existe identidad entre el concepto de "aporte" de los socios en caso de aumento de capital, y el aumento de capital que se produce en sociedades preexistentes como consecuencia de un acuerdo de escisión. Además, no siempre se producen aumentos de capital como consecuencia de la escisión. Por ello, en términos generales, es más exacto hablar de ajustes en el capital social, como hace correctamente la LGS. 
b) La subsistencia de la persona jurídica escindente, en la escisión segregación, impropia o parcial, con el ajuste respectivo de su capital, salvo excepciones. Siguiendo nuevamente a Elías (2001):

Con respecto a la persona jurídica escindente, que es la materia de esta parte del comentario, ello significa, en primer lugar, que ella subsiste con al menos una porción o bloque de su patrimonio original; $y$, en segundo lugar, que debe ajustar su capital social, sea por disminución o por aumento del mismo, con motivo del traspaso de uno o más bloques patrimoniales a otras sociedades. [...]

Finalmente, también existen casos en que no es necesario realizar ajustes en el capital social: (i) Si los bloques patrimoniales escindidos se traspasan con activos y pasivos del mismo valor; (ii) $\mathrm{Si}$, habiendo un resultado neto negativo para la escindente, ella decide cargarlo contra utilidades o reservas libres, presentes o futuras; y (iii) Si habiendo un resultado neto positivo para la escindente, ella decide no capitalizarlo. (p. 804)

Por nuestra parte, coincidimos con Elías en el sentido de que la extinción de la sociedad escindente en el caso de la escisión total o propia, y la subsistencia de la sociedad escindente en el caso de la escisión parcial o impropia, constituyen en conjunto, y atendiendo a las particularidades de cada uno de los supuestos mencionados, uno de los presupuestos de la escisión.

Finalmente, en esta parte del presente trabajo, relacionado con los caracteres esenciales de escisión, no podemos dejar de mencionar el caso de las denominadas escisiones subjetivas, que son materia de especial atención, fundamentalmente en sus aspectos tributarios. Conforme lo hemos descrito, lo común en una escisión es que los socios de la sociedad escindida reciban acciones de las empresas beneficiarias en proporción a su participación en el capital social; empero, en una escisión subjetiva, se produce una reagrupación de socios sin responder a la proporción de sus aportes, porque así lo acuerdan los socios entre ellos, lo cual está explícitamente permitido por el artículo 368 de la LGS cuando permite el pacto en contrario a la proporcionalidad, señalando además que dicho pacto puede disponer que uno o más socios no reciban acciones o participaciones de alguna o algunas de las sociedades beneficiarias, e implícitamente permitido por el inciso 5 del artículo 372 de la LGS cuando establece que dentro del proyecto de escisión se debe indicar la relación del reparto, 
entre los accionistas o socios de la sociedad escindida, de las acciones o participaciones a ser emitidas por las sociedades beneficiarias, sin señalar que se debe respetar las proporcionalidades preexistentes. En nuestra opinión, las denominadas escisiones subjetivas encuadran dentro del concepto de escisión previsto en la LGS, y como consecuencia de ello gozan del régimen legal y tributario previsto para este tipo de reorganización societaria. Elías (2001, pp. 797-798), sobre este tema, considera que las escisiones subjetivas no eran modalidades distintas de escisiones, sino de variantes que pueden ocurrir dentro de cualquier forma legal de escisión.

\section{Tres importantes elementos a tomar en cuenta por las sociedades participantes en una escisión}

\subsection{La personalidad jurídica en el derecho societario peruano}

Uno de los principios fundamentales del derecho societario consiste en la limitación de responsabilidad, que a su vez es consecuencia del reconocimiento legal de la personalidad jurídica de las sociedades, que conduce a la distinción entre el patrimonio de la sociedad y el patrimonio de sus socios o accionistas. En el Perú, el artículo 6 de la LGS dispone que: "La sociedad adquiere personalidad jurídica desde su inscripción en el Registro, y la mantiene hasta que se inscribe su extinción". Según un importante sector de la doctrina, cuya posición compartimos, la personalidad jurídica de las sociedades nace como una ficción legal, que, al ser reconocida por una norma legal, se convierte en una realidad jurídica.

Cabanellas de las Cuevas (1993) expresa esta idea en la forma siguiente:

En tal contexto, característico de las sociedades, resulta más simple, claro y económico imputar los derechos y obligaciones emergentes de la actividad colectiva a un único ente, con el cual mantienen determinadas relaciones jurídicas los terceros y los socios. La persona de existencia ideal es así "una realidad jurídica que la ley reconoce como medio técnico para que todo grupo de individuos pueda realizar el fin lícito que se propone". (p. 34)

Ahora bien, el jurista peruano Elías (2001) define la personalidad jurídica de la siguiente manera:

Se entiende que la personalidad jurídica es la que detentan entes jurídicos distintos de las personas físicas, que tienen una voluntad propia, 
están dotadas de una organización estable y son sujetos de derecho diferentes a sus socios, administradores o representantes. (p. 21)

Por su parte, Capilla Roncero, citado por Seoane Linares (2005, p. 67), entiende el principio de separación de la personalidad jurídica como:

El reconocimiento jurídico formalista de los entes dotados de personalidad jurídica que consideran a estos como sujetos de derechos subjetivos y relaciones jurídicas, autónomos y ajenos respecto de las concretas personas físicas que, integradas en la organización del ente, controlan sus destinos.

Asimismo, Seoane Linares define como uno de los principios de la persona jurídica el siguiente:

La persona jurídica es una entidad distinta a sus miembros, así mismo su patrimonio es propio y distinto al de sus miembros. Este principio se inspira en la máxima de Ulpiano: “Si quid universitatis debetur, singuli non debetur: nec quod debet universitas, singuli debent", Digesto 3, 4, 7, 1 (Lo que adeuda la persona jurídica, no lo adeudan sus miembros; asimismo, lo que adeudan los miembros, no lo adeuda la persona jurídica). Este principio es fundamental en la estructura de la persona jurídica, y fue recogido por la gran mayoría de legislaciones modernas; por ejemplo el artículo n. ${ }^{\circ} 78$ del Código Civil dispone que "La persona jurídica tiene existencia distinta de sus miembros y ninguno de estos o todos ellos tienen derecho a su patrimonio ni a satisfacer sus deudas". (2005, p. 31)

Entre los autores peruanos, Elías (2001) señala, entre otros efectos de la personalidad jurídica -denominación o razón social, domicilio, patrimonio propio, capacidad como sujeto de derechos, duración, objeto, órganos sociales, representación, parentesco y nacionalidad-, el de...

[...] independizarla totalmente de sus socios en los temas de responsabilidad ante terceros y de responsabilidad y representación judicial. En resumen, la personalidad jurídica genera independencia entre la sociedad y sus socios. Cosa distinta es una de otros. No puede haber confusión en ninguno de los aspectos antes mencionados. (p. 24)

Como refiere el tratadista español Embid (1987, p. 1035), la consecuencia más importante de la atribución de personalidad jurídica a la sociedad anónima, deviene en la irresponsabilidad de sus integrantes respecto de las deudas sociales. 
El principio de limitación de la responsabilidad ha sido recogido, guardando coherencia con el reconocimiento de la personalidad jurídica de las sociedades, por el artículo 31 de la LGS, que dispone a la letra lo siguiente: "El patrimonio social responde por las obligaciones de la sociedad, sin perjuicio de la responsabilidad personal en aquellas formas societarias que así lo contemplan". La norma mencionada establece con toda claridad que, en las sociedades de responsabilidad limitada, como es el caso de la sociedad anónima, la responsabilidad por las obligaciones de la sociedad se encuentra limitada a su patrimonio, entendido este como el conjunto de activos y pasivos.

\subsection{La pertenencia o no a grupos de sociedades}

Según Echaíz (2002, p. 71), “El grupo de empresas es un fenómeno derivado de la concentración empresarial, de naturaleza multiarticulada, constituido por o dos o más empresas jurídicamente autónomas, en el cual existe una dirección unificada...". Y el mismo autor indica que:

Son tres las características de los grupos de empresas: autonomía jurídica, relación de dominación-dependencia y dirección unificada. La autonomía jurídica significa que las empresas integrantes del grupo conservan su propio objeto, denominación, titular o titulares, plantel de trabajadores, así como la titularidad de todo derecho que legal o contractualmente les corresponda y las obligaciones que hayan contraído. (2002, p. 77)

Por nuestra parte, en un trabajo anterior hemos señalado lo siguiente:

[...] los grupos de empresas se forman con el fin de encarar estrategias de crecimiento, buscando la apertura del mercado, una mejor posición en él o el avance económico y social de un área ya ensanchada. La figura del grupo, de este modo, permite a las empresas optimizar la utilización de sus recursos, multiplicar la producción, afirmar una sólida posición en el mercado de consumidores y poner en marcha una organización económica de gran significación e importancia. Cabe destacar que el simple control de una empresa por parte de otra no constituye la formación de un grupo de empresas. Para que exista un grupo de empresas deben concurrir tres elementos: autonomía jurídica de cada empresa, relación de dominación-dependencia entre ellas y una dirección unificada. (Hundskopf, 2004, p. 197) 
Basándonos en lo anterior, podríamos concluir que las sociedades integrantes de un grupo empresarial mantienen, de manera independiente y autónoma, la titularidad de todo derecho y de toda obligación. De acuerdo a ello, queda claro que, en principio, las obligaciones laborales, tributarias y comerciales de una de las empresas integrante de un grupo empresarial, no pueden ser trasladadas a las demás, salvo que integren los pasivos que conforman el bloque patrimonial transferido.

Cabe señalar que en el Perú no existe ninguna norma que regule, con carácter general, a los grupos de sociedades, razón por la cual no contamos con una definición legal respecto del control de sociedades, que permita establecer de manera objetiva en qué casos nos encontramos ante un grupo de empresas o sociedades. Sin embargo, de manera referencial, podemos mencionar la definición contenida en el Reglamento de Propiedad Indirecta, Vinculación y Grupo Económico-Resolución Conasev n. ${ }^{\circ}$ 090-2005-EF/94.10, publicado en el diario oficial El Peruano con fecha 28 de diciembre de 2005, aplicable a las personas naturales o jurídicas que se encuentran sometidas al control y supervisión de la Comisión Nacional Supervisora, cuyo artículo 7 define al grupo económico como "...el conjunto de personas jurídicas, cualquiera sea su actividad u objeto social, que están sujetas al control de una misma persona natural o de un mismo conjunto de personas naturales".

El artículo 6 de la misma norma establece que se considera control "la capacidad de dirigir la administración de la persona jurídica", y agrega que...

[...] salvo prueba en contrario, se presume la existencia de control en los siguientes casos:

a) Cuando a través de la propiedad directa o indirecta de acciones, contratos de usufructo, prenda, fideicomiso o similares acuerdos con otros accionistas o cualquier otro acto jurídico, se pueden ejercer más de la mitad de los derechos de voto en la junta general de accionistas de dicha persona jurídica, salvo que en la misma persona jurídica, un tercero se encuentre en la situación prevista en el inciso b) siguiente;

b) Cuando sin contar con más de la mitad de los derechos de voto en la junta general de accionistas de dicha persona jurídica, pueden designar o remover a la mayoría de los miembros del directorio. 
Encontramos normas sectoriales similares, orientadas a las empresas bajo el ámbito de supervisión de la Superintendencia de Banca, Seguros y AFP. Asimismo, cabe mencionar que el control de una sociedad por otra es una forma de vinculación, en este caso, derivada de la titularidad de suficientes acciones que permiten a la sociedad dominante adoptar los acuerdos que estime necesarios en la sociedad dominada. Sin embargo, a pesar de que la subsidiaria se encuentra bajo una relación de dominación-dependencia respecto de la empresa dominante, se trata de una persona jurídica distinta, con autonomía en cuanto al patrimonio y a los derechos y obligaciones que asume.

Ahora bien, como señalamos líneas arriba, la sola existencia de control no importa necesariamente la configuración de un grupo de sociedades o grupo económico, pues para ello son indispensables además la dirección unificada y la autonomía jurídica. Sin embargo, consideramos que, aun partiendo del supuesto en que nos encontremos ante un grupo económico, no es posible responsabilizar a la sociedad dominante por los actos realizados por la dominada, bajo las normas del ordenamiento jurídico peruano.

\subsection{Sobre la posible aplicación de la doctrina del levantamiento del velo societario}

Como hemos referido anteriormente, el artículo 6 de la LGS establece que la sociedad adquiere personalidad jurídica desde su inscripción en el Registro y la mantiene hasta que se inscribe su extinción. A su turno, el artículo 31 de la misma norma consagra el principio de limitación de responsabilidad, señalando que el patrimonio de la sociedad, y no el patrimonio de sus socios, responde por las obligaciones sociales.

La LGS no contempla, en ninguno de sus artículos, la opción de aplicar la teoría o doctrina del levantamiento del velo societario tan de moda actualmente. Sin embargo, el tema sí ha sido objeto de desarrollo, a nivel doctrinario y de aplicación jurisprudencial.

De la vasta doctrina existente en nuestro país respecto al levantamiento del velo societario, consideramos pertinente exponer los presupuestos que reconocidos juristas consideran que deben concurrir, para poder llevar a cabo la aplicación de la teoría o doctrina del levantamiento del velo societario en los grupos de sociedades. A continuación, señalamos los referidos presupuestos, los cuales son los siguientes: 1) Situación de control; 2) Situación de abuso de derecho o fraude a la ley; y 3) Respeto del principio de subsidiariedad. 
1. Según la doctrina, habrá situación de control por la existencia de al menos dos sociedades: la dominante y la dominada, que se encuentran en situación de dominación-dependencia.

2. Respecto a la situación de abuso de derecho o fraude a la ley, ciertamente la figura del "abuso del derecho" no es una institución nueva, sino que sus orígenes se remontan hasta el derecho romano. En el caso peruano, el artículo II del título preliminar del Código Civil consagra esta figura, al disponer que la ley no ampara el abuso del derecho. Con respecto a este punto, el reconocido jurista León Barandiarán, citado por Espinoza (2011), señala que:

Se incurre en abuso de derecho cuando, en el ejercicio de tal derecho, el titular se excede manifiestamente de los límites de la buena fe de modo que dicho ejercicio no se compatibiliza con la finalidad institucional y la función social en razón de las cuales se ha reconocido el respectivo derecho. (p. 90)

Asimismo, se debe considerar que, para la aplicación de esta institución jurídica, la doctrina y la jurisprudencia han establecido ciertos criterios. En efecto, Espinoza (2011) indica que:

La doctrina nacional se ha preocupado por delimitar la noción del abuso de derecho y por proporcionar los siguientes elementos de juicio:

a) tiene como punto de partida una situación jurídica subjetiva;

b) se transgrede un deber jurídico genérico (buena fe, buenas costumbres, inspiradas en el valor solidaridad);

c) es un acto ilícito sui generis;

d) se agravian intereses patrimoniales ajenos y no tutelados por una norma jurídica específica;

e) ejercicio del derecho subjetivo de modo irregular;

f) no es necesario que se verifique el daño; $y$

g) su tratamiento no debe corresponder a la responsabilidad civil sino a la Teoría General del Derecho. (p. 90)

Ahora bien, dentro de la Teoría General del Abuso del Derecho, la doctrina ha desarrollado una subespecie de la misma, denominada "abuso de la personalidad jurídica", siendo el caso que distintos autores se han preocupado por delimitar su concepto y características. 
$\mathrm{Al}$ respecto, cabe precisar que el inciso 13 del artículo 2 de la Constitución Política del Estado consagra, entre los derechos de la persona, el de asociarse con fines lícitos. En el caso de las sociedades, este derecho de asociación es complementado con lo dispuesto por el artículo 78 del Código Civil, según el cual la persona jurídica es distinta de sus miembros, por lo que ninguno de éstos es propietario o asume las deudas contraídas por la persona jurídica.

Sin embargo, existen casos en los cuales el ejercicio de este derecho de asociación se produce de manera irregular, con el fin de evadir el cumplimiento de obligaciones o cometer fraude, desviándose así completamente de los fines para los cuales se consagra jurídicamente la personalidad jurídica.

El doctor Fernández (2001), quien comenta la aplicación de la Teoría del Abuso de la Personalidad Jurídica en el Derecho de las Personas, señala que:

El abuso de la personalidad jurídica es aquella situación o circunstancia en la cual una organización de personas o ciertas personas de ésta utilizan las ventajas que otorga la formalidad que se obtiene con la inscripción de dicha organización en el registro, para obtener beneficios en su provecho o en el de terceros, al margen de los propios intereses de la persona jurídica. Es decir, son los seres humanos integrantes de la organización los que emplean dichas ventajas en su favor o para cometer un fraude a la ley. (p. 57)

En cuanto a la figura del fraude a la ley, el doctor Torres (2001) define el fraude a la ley como sigue:

Por el fraude a la ley se evade la aplicación de una ley (ley defraudada) amparándose en otra ley (ley de cobertura), que solo de modo aparente protege el acto realizado, caso en el cual debe aplicarse la ley que se ha tratado de eludir o, si ello no es posible, anular el acto, independientemente de que con este se haya o no causado daño. (p. 573)

En consecuencia, si se advierte que la reorganización societaria ha tenido una razón de ser, es decir que no se ha efectuado de manera caprichosa y sin un sentido real, sino que ha existido una justificación que se advierta en los hechos - por ejemplo, transferir a nuevos accionistas la empresa escindida; utilizar el bloque escindido para otros fines comerciales; obtener el financiamiento de operaciones, entre otras justificaciones económicas y corporati- 
vas-, no estaremos por consiguiente frente a un uso abusivo ni fraudulento de la reorganización societaria, que permita eventualmente a un juez o árbitro proceder válidamente al levantamiento del velo societario de una o más de las sociedades participantes en la reorganización societaria.

3. Finalmente, respecto del principio de subsidiariedad, este presupuesto implica que la teoría o doctrina del levantamiento del velo societario debe aplicarse como última ratio; es decir, cuando el problema no pueda ser resuelto mediante el empleo de otros mecanismos que el propio derecho franquea. En otras palabras, la teoría o la doctrina del allanamiento de la personalidad jurídica debe ser siempre aplicada como una solución de segundo rango, residual o supletoria, pero jamás como la primera solución a utilizar.

Conforme al análisis efectuado sobre la aplicación de la teoría o doctrina del levantamiento del velo societario, el principio general en el derecho societario peruano, es la personalidad jurídica independiente de las sociedades $\mathrm{y}$, en consecuencia, la limitación de responsabilidad. Si bien es cierto que existe teóricamente la posibilidad de aplicar la doctrina del levantamiento del velo societario en determinados casos de abuso del derecho y fraude a la ley, debidamente comprobados, y conforme a estrictas reglas lógicas establecidas a través de la jurisprudencia, hay que analizar cada caso concreto, y le corresponderá al juez o al árbitro, de acuerdo a su libre discrecionalidad, y como última ratio, definir lo necesario en aras de acceder a la justicia. Son múltiples los casos, sobre todo en materia laboral y comercial, en que los jueces ya han aplicado dicha teoría o doctrina, y por lo tanto se cuenta ya con una importante jurisprudencia.

\section{Mecanismos de protección de los derechos de los acreedores a terceros en las operaciones societarias de escisión}

\subsection{El derecho de oposición de los acreedores en la escisión}

Como hemos señalado anteriormente, la escisión implica la transmisión en bloque y a título universal de uno o más bloques patrimoniales de la sociedad escindente. Asimismo, en el caso de la escisión propia o total, su entrada en vigencia determina la extinción de la sociedad escindente. 
De acuerdo con lo dispuesto por el artículo 378 de la LGS, a partir de la fecha de entrada en vigencia de la escisión (aunque supeditada a la inscripción de la escisión en Registros Públicos), las sociedades beneficiarias asumen automáticamente las operaciones, derechos y obligaciones de los bloques patrimoniales escindidos, y cesan respecto de dichos bloques patrimoniales, las operaciones, derechos y obligaciones de las sociedades escindidas, ya sea que se extingan o no.

Como es evidente, los acreedores de las sociedades intervinientes pueden ver afectadas sus posibilidades de cobro, en caso de que sus créditos sean asumidos por sociedades preexistentes o nuevas, cuyos patrimonios sean menos sólidos que el de las sociedades que contrajeron inicialmente las obligaciones con dichos acreedores.

El derecho de oposición al acuerdo de escisión, previsto por el artículo 383 de la LGS (que a su vez remite al procedimiento dispuesto por el artículo 219 de la LGS, referido al derecho de oposición de los acreedores en caso de reducción de capital), conjuntamente con la obligación de publicar el acuerdo de escisión, contenida en el artículo 380 de la LGS, constituyen mecanismos de protección para los acreedores de todas las sociedades participantes en una escisión, quienes pueden ver afectado su derecho de cobro como consecuencia de la entrada en vigencia de la escisión.

Respecto de la obligación de publicar el acuerdo de escisión, Elías (2001) indica que:

[...] nuestras leyes societarias, coincidentes con otras legislaciones, admiten el principio por el cual los acuerdos de reorganización de sociedades deben ser dotados de formas especiales de publicidad, dada su trascendencia. En el caso concreto de la escisión, esta forma especial de publicidad del artículo 380 tiene objetivos más amplios que en la transformación, según comentamos al analizar el artículo 337 de la Ley, y también de mayor amplitud a la que resulta del propio texto del artículo bajo comentario. En efecto, la comunicación de los acuerdos de la escisión procura un doble fin: (i) Alertar a los acreedores de cada persona jurídica participante, para que puedan ejercer el derecho de oposición previsto en el artículo 383, que comentamos más adelante; y (ii) Poner estos acuerdos en conocimiento de los propios socios de cada sociedad participante, para los efectos del derecho de separación contemplado en el artículo 385. (p. 381) 
El mismo autor, en su comentario al artículo 383 de la LGS, que regula el derecho de oposición a la escisión, señala:

[...] en la escisión de sociedades, el artículo 383 de la Ley otorga a los acreedores de cualquiera de las sociedades participantes el derecho de oponerse a la escisión, si considera que a raíz de ella su crédito no va a encontrarse suficientemente garantizado, o que con motivo de la operación su crédito o créditos han quedado en situación de peligro o de menor solidez.

Este derecho tiene especial aplicación en las escisiones, desde que se trata de operaciones en las que los bloques patrimoniales de las sociedades escindentes se transmiten en bloque, o sea sin necesidad de notificación o acuerdo con los acreedores de las sociedades intervinientes. El derecho de oposición reemplaza entonces a esa carencia. Adviértase que, en cualquier forma de escisión, los acreedores pueden considerar que el patrimonio de las sociedades participantes, o el de la sociedad que asumió el crédito, al término de la operación de escisión, es menos sólido que el de la sociedad o del grupo contra los que detentaba originalmente el crédito o créditos. (Elías, 2001, p. 834)

Del análisis de la norma bajo comentario, complementada con el artículo 380 de la LGS, se desprende, en nuestra opinión, que el derecho de oposición a la escisión es claramente un mecanismo de protección a los acreedores, no solamente de las sociedades escindidas, sino de todas las sociedades participantes en una operación de escisión.

\subsection{Plazo para oponerse a la escisión, y la naturaleza de dicho plazo}

El artículo 376 de la LGS dispone que las juntas generales o asambleas de cada una de las sociedades participantes, aprueban el proyecto de escisión y fijan una fecha común de entrada en vigencia de la escisión.

De acuerdo con lo dispuesto por el artículo 380 de la LGS, cada uno de los acuerdos de escisión se publica por tres veces, con cinco días de intervalo entre cada aviso. Los avisos podrán ser publicados en forma independiente o conjunta por las sociedades participantes.

Como ya hemos señalado, el artículo 383 de la LGS remite, para el ejercicio del derecho de oposición a la escisión, al mecanismo previsto en el artículo 219 del mismo cuerpo legal, según el cual la oposición debe ejercerse ante el juez, a través del proceso sumarísimo, dentro del 
plazo de treinta días, contados a partir de la fecha de publicación del último aviso a que se refiere el artículo 380 de la LGS.

En la Exposición de Presentación del Proyecto de Ley General de Sociedades ${ }^{7}$, efectuada por el presidente de la Comisión Redactora, doctor Enrique Normand Sparks, a la Comisión Revisora, presidida por el doctor Carlos Torres y Torres Lara, se expresa lo siguiente:

Todos los plazos de la ley se han convertido en plazos de caducidad. Se han eliminado los plazos de prescripción. El derecho societario es un derecho rápido, dinámico, es un derecho que debe ser claro y muy bien delimitado. En consecuencia, no se condice con la prescripción, que tiene elementos como la suspensión, la interrupción y la necesidad de ser invocada. Contrapuesta a ello, la caducidad mata el derecho y la situación queda determinada de manera clara y definitiva.

Comentando lo señalado por el doctor Normand, en relación con el artículo 49 de la LGS -que fija un plazo de caducidad de dos años para las pretensiones de cualquier socio o tercero, por actos $\mathrm{u}$ omisiones relacionados con derechos otorgados por la LGS, respecto de los cuales no se haya establecido expresamente un plazo-, el doctor Elías (2001) señala:

Dos son los aspectos de esta cita que nos parece pertinente destacar. El primero se relaciona con el plazo genérico fijado. Se ha tomado en cuenta que las sociedades establecen un cúmulo de complejas relaciones y se convierten así en ejes sobre los que giran una serie de intereses distintos: los de los socios, diversos acreedores, terceros y el interés general que exige otorgar dinamismo a un agente activo del mercado. Por ello se ha considerado que dos años es un plazo adecuado para la defensa de los intereses de la sociedad, de socios $\mathrm{y}$ de terceros diligentes, sin que llegue a ser demasiado extenso como para generar incertidumbre jurídica. Estas son consideraciones fundamentales, a las que el derecho societario debe otorgar la primera prioridad. (p. 102)

De lo expresado por los autores arriba citados, se desprende con toda claridad que la intención del legislador societario peruano, al establecer plazos de caducidad, y además relativamente cortos, para el ejercicio de pretensiones relacionadas con derechos otorgados por la LGS, consiste

7 La Exposición de Presentación fue publicada en el diario oficial El Peruano, el 23 de abril de 1997. 
en brindar seguridad jurídica a los operadores del derecho, pues se trata de plazos perentorios y fatales, lo que se condice y guarda coherencia con el dinamismo inherente al derecho mercantil.

Ahora bien, todos los trabajadores de las empresas que intervienen en una operación societaria de escisión, tienen la calidad de acreedores, y por lo tanto tienen pleno derecho a oponerse a la escisión, siempre y cuando lo hagan dentro del plazo indicado anteriormente, es decir, dentro de los treinta días contados a partir de la fecha de publicación del último de tres avisos.

\subsection{Impugnaciones de los acuerdos de escisión}

Si fuera el caso que alguno o algunos de los trabajadores sean además accionistas, estarían legitimados para ejercer el derecho de impugnación de los acuerdos de las juntas generales de accionistas a través de los cuales se aprobó la escisión, siguiendo al efecto el procedimiento de impugnación regulado por el artículo 139 y siguientes de la LGS, el cual, como se sabe, contiene un conjunto de reglas procesales especiales, entre las cuales están los plazos de caducidad establecidos en el artículo 142, y que son de dos meses a partir de la fecha de adopción del acuerdo si el accionista concurrió a la junta, tres meses si no concurrió, y tratándose de acuerdos inscribibles, dentro del mes siguiente a la inscripción.

De otro lado, cualquier acreedor de una sociedad, sea o no trabajador, invocando legítimo interés, puede interponer judicialmente la pretensión de nulidad de los acuerdos societarios en virtud de los cuales se aprobó dicha escisión, conforme a lo previsto por el artículo 150 de la LGS, que transcribimos a continuación:

Procede acción de nulidad para invalidar los acuerdos de la junta contrarios a normas imperativas o que incurran en causales de nulidad previstas en esta ley o en el Código Civil. Cualquier persona que tenga legítimo interés puede interponer acción de nulidad contra los acuerdos mencionados en el párrafo anterior, la que se sustanciará en el proceso de conocimiento. La acción de nulidad prevista en este artículo caduca al año de la adopción del acuerdo respectivo.

Finalmente, y como última posibilidad, cuentan con la pretensión judicial de nulidad contra una escisión inscrita en el Registro, la cual está prevista en el artículo 330, el que a su vez se remite a los artículos 365 y 366 de la LGS, aplicables a la fusión, por lo cual sólo puede basarse en la 
nulidad de los acuerdos de las juntas generales de las sociedades que participaron en la escisión, debiendo dirigir la pretensión contra la sociedad escindida o contra la sociedad beneficiaria del o los bloques patrimoniales, tramitándose dicha pretensión en el proceso abreviado y debiéndose necesariamente interponer dentro del plazo de caducidad de seis meses, contados a partir de la fecha de la inscripción en el Registro de la escritura pública de escisión. Sobre esta última posibilidad, debe tomarse en cuenta que la declaración de nulidad no afecta la validez de las obligaciones nacidas después de la entrada en vigencia de la escisión, siendo solidariamente responsables todas las sociedades que participaron en la escisión, frente a los acreedores de tales obligaciones.

\section{Efectos en el capital social de las sociedades que intervienen en un procedimiento de escisión}

Conforme a lo establecido en el artículo 367 de la LGS, tanto en la escisión división como en la escisión segregación, los bloques patrimoniales son transferidos a nuevas sociedades o absorbidos por sociedades ya existentes, o ambas cosas a la vez; lo cual quiere decir que si se opta por la primera opción, el o los bloques patrimoniales constituyen el o los aportes necesarios para la constitución de las sociedades, en cuyo caso las acciones que se crean y emitan por la nueva sociedad, le corresponderán a los socios de la sociedad escindida, quienes las reciben en la misma proporción en que participan en el capital de ésta, salvo pacto en contrario, el cual puede disponer que uno o más socios no reciban acciones de alguna o algunas de las sociedades beneficiarias, y si se opta por transferir los bloques patrimoniales a sociedades ya existentes, el efecto del capital social, y en lo que se refiere a la creación y emisión de acciones, dependerá del valor neto del bloque patrimonial transferido.

En ese sentido, para que una escisión implique en la sociedad receptora un aumento de capital, el bloque patrimonial transferido debe necesariamente tener un valor neto positivo, y solamente en ese caso la sociedad receptora estará en la obligación de emitir nuevas acciones a favor de los socios o accionistas de la sociedad escindida. Sin embargo, el bloque patrimonial materia de una reorganización societaria y específica de una escisión, puede tener un valor neto negativo o neutro, y aun así ser transferido a la sociedad receptora, situación que no implica un aumento de capital y una posterior emisión de acciones. En palabras de Salas (2002): 
Distinto y opuesto es el caso en que no existe tal superávit y se está frente a un bloque cuyo valor neto es negativo. Al trasladarse las cuentas que integran ese bloque, el capital en él incorporado no existe, pues su valor ha sido íntegramente absorbido por las pérdidas o por el valor de los pasivos superior al de los activos. En este caso, nada hay que sumar, ni por ello podrá producirse aumento alguno en el capital de la receptora. Obviamente, si no hay aumento, no habrá nuevas acciones por emitir, ni sociedad legítima que las reciba. (p. 164)

No obstante, ello no significa necesariamente que en el caso de la escisión segregación, la sociedad que se desprenda del bloque patrimonial o la que lo reciba, se vea perjudicada, pues existen elementos que hacen atractivo un bloque patrimonial por más que éste tenga un valor contable negativo o incluso neutro, es decir, de valor cero. La sociedad receptora podría estar dispuesta a recibir una unidad de negocio contablemente negativa o neutra, pero que contenga valores intangibles que hagan que la sociedad receptora esté dispuesta a otorgar acciones por ello.

Así pues, resulta claro que no toda escisión debe generar necesariamente un aumento de capital en la sociedad receptora del bloque patrimonial y la consiguiente emisión de acciones a favor de los accionistas de la sociedad escindida, porque detrás de toda operación empresarial hay razones de negocio totalmente distintas, dependiendo de cuáles sean los intereses de las partes en un procedimiento de reorganización societaria.

Respecto al valor del bloque patrimonial, objeto de transferencia en una operación de escisión, es importante tener presente lo expuesto en los incisos d y e del artículo 124 del Reglamento del Registro de Sociedades. Respecto al inciso d, este establece que en caso sea positivo el valor neto del bloque patrimonial que se transfiere, debe indicarse el monto en el que se aumente el capital de la sociedad receptora, y tratándose de la sociedad que se constituye por la escisión, debe indicarse el porcentaje de participación y el número de acciones o participaciones sociales que la nueva sociedad entregará a los socios de la sociedad que se escinde total o parcialmente. $\mathrm{Y}$ el inciso e establece que en caso sea negativo el valor neto del bloque patrimonial que se transfiere, se dejará constancia de su monto y esa circunstancia producirá que la sociedad receptora no aumente su capital ni emita nuevas acciones, estableciendo además que tratándose de una escisión por constitución se dejará constancia que la nueva sociedad no emite acciones o participaciones sociales a favor de los socios de la sociedad que se extingue por la escisión. 
De lo expuesto, nótese que no se menciona expresamente la posibilidad de que el valor neto sea neutro, es decir, cero. Sin embargo, al establecer la norma según la cual el valor del bloque patrimonial puede ser positivo o negativo, queda claro, a nuestro modo de ver, que también se admite la posibilidad de que el bloque patrimonial sea neutro, es decir, ni positivo ni negativo.

Debe tenerse en cuenta que una operación de desconcentración empresarial como es la escisión, resulta siendo extremadamente compleja en comparación a lo sencillo que puede presentarse su explicación teórica, y es por ello que el legislador no se ha visto en la necesidad de hacer mención expresa del supuesto en el cual el valor neto del bloque patrimonial sea neutro, ya que el derecho no debe intentar normas específicas para cada caso concreto, y por el contrario, en términos de buena técnica legislativa, lo aconsejable es regular supuestos generales y plantear las excepciones pertinentes hasta donde sea razonablemente posible. Por lo tanto, en los casos excepcionales en los que estemos frente a una escisión donde se pretenda transferir un bloque patrimonial con valor neto neutro, con base en una interpretación teleológica (técnica de la hermenéutica que busca extraer la finalidad de la norma), llegaremos inevitablemente a la conclusión según la cual sí será posible realizarla, toda vez que el propósito de la norma es regular los supuestos en los cuales no se produzca un aumento de capital por parte de la beneficiaria, debido a que, como ya hemos mencionado, el bloque patrimonial segregado y recibido por la sociedad beneficiaria, tiene valor neto, negativo o neutro.

A nuestro modo de ver, hizo bien el RRS en sancionar los efectos jurídicos de la escisión al exigir que para descripción de ésta la escritura pública pertinente deberá contener, además de lo establecido en el artículo 382 de la LGS, indicaciones especiales como los incisos d y e, referidos a los efectos jurídicos de esta operación, es decir, si el valor neto del bloque patrimonial transferido es positivo o negativo, pues de esta manera el legislador registral asumió una concepción subjetiva respecto al "valor", que de todas maneras lo tiene, y quién mejor que las partes para dar contenido económico a determinados bienes. En efecto, existen bienes cuyo valor no se desprende de una valoración objetiva, como en los casos donde lo que contablemente valdría el bloque patrimonial no se condice con el valor que representa para las partes intervinientes en la operación societaria de escisión. Es la voluntad negocial la que imprime un concepto de valor basado en elementos intangibles, que solo son apreciables por los agentes económicos que participan en la operación societaria en cuestión. 
A mayor abundamiento, debe tenerse en cuenta que existen innumerables métodos de valorización y que cada uno de estos responde a la naturaleza económica de cada realidad distinta de negocio, por lo tanto, consideramos que hubiera sido desacertado por parte del legislador restringir los posibles criterios de valorización admitidos legalmente. Consideramos que la LGS ha hecho bien en otorgar a las partes libertad para emplear los criterios de valorización que mejor les parezca, y ello porque quienes están en mejor posición para determinar el valor real del bloque patrimonial a ser transferido, son las mismas partes intervinientes. Debe tenerse presente asimismo, que cada bloque patrimonial puede tener un valor oculto que no se ve reflejado en los estados financieros, pero que sin embargo pueden incrementar significativamente el valor del bloque patrimonial en cuestión.

La institución de la escisión, sin duda, es sumamente interesante, tanto en su enfoque teórico como en su aplicación práctica, y por ello, en atención a la praxis societaria y a la casuística consultada, hemos formulado algunos apuntes sobre temas concretos teórico-prácticos.

\section{Referencias}

Beaumont, R. (1998). Comentarios a la nueva Ley General de Sociedades. Lima: Gaceta Jurídica.

Bravo, J. (2003). Derecho tributario. Reflexiones. Lima: Jurista Editores.

Broseta, M. (2009). Manual de derecho mercantil (volumen I). Madrid: Tecnos.

Cabanellas de las Cuevas, G. (1993). Derecho societario (tomo 3). Buenos Aires: Editorial Heliasta.

Castle Álvarez-Maza, P. (2002). ¿La reorganización simple o simple aporte? Advocatus, 7.

Echaíz, D. (2002). La empresa en el derecho moderno. Lima: Gráfica Horizonte.

Elías, E. (2001). Derecho societario peruano. La Ley General de Sociedades del Perú. Trujillo: Normas Legales.

Embid, J.M. (1987). Grupos de sociedades y accionistas minoritarios. Ministerio de Justicia. Madrid: Secretaría General Técnica.

Fernández, C. (2001). Apuntes sobre el abuso de la personalidad jurídica. Advocatus, 4.

Hundskopf Exebio, O. (2004). Derecho comercial. Temas societarios (tomo III). Fondo de Desarrollo Editorial de la Universidad de Lima. 
Hundskopf Exebio, O. (2009). Fecha de entrada en vigencia de una escisión con transferencia de un bloque patrimonial que incluye activos y pasivos. Derecho comercial. Temas societarios (tomo IX). Fondo de Desarrollo Editorial de la Universidad de Lima.

Israel Llave, L., \& Filomeno Ramírez, A. (agosto, 2003). La fusión y la escisión en la nueva Ley General de Sociedades. Tratado de derecho mercantil (tomo I). Lima: Gaceta Jurídica.

Ley de Sociedades Mercantiles, Ley n. ${ }^{\circ}$ 16123, promulgada el 27 de julio de 1966, y sus modificaciones.

Ley General de Sociedades, Ley n. ${ }^{\circ} 26887$, promulgada el $1^{\circ}$ de enero de 1998.

Otaegui, J. (1981). Fusión y escisión de sociedades comerciales. Buenos Aires: Ábaco.

Real Academia Española. (2001). Diccionario de la lengua española (22a ed.). Madrid.

Reyes, F. (2006). Derecho societario (tomo II). Bogotá: Temis.

Richard, H.E., \& Muiño, O.M. (2004). Derecho societario (5 ${ }^{\text {a }}$ ed.). Buenos Aires: Astrea.

Salas, J. (2002). El valor neto negativo del bloque patrimonial que se transfiere en los procesos de reorganización societaria. Ius et Veritas, 25.

Seoane, M. (2005). Personas jurídicas: principios generales y su regulación en la legislación peruana (2a ed.). Lima: Editorial Grijley.

Torres, A. (2001). Acto jurídico ( $2^{\mathrm{a}}$ ed.). Lima: Idemsa.

Uría, R., Menéndez, A., \& Iglesias, J. (1999). Fusión y escisión de sociedades. Curso de Derecho Mercantil (vol. II, tomo I). Madrid: Civitas.

Verón, A.V. (2008). Tratado de las sociedades anónimas (tomo V). Buenos Aires: La Ley. 
